\title{
Infrastructuring ESTS
}

\section{ESTSEDITORIAL COLLECTIVE:}

\author{
AALOK KHANDEKAR \\ INDIAN INSTITUTE OF \\ TECHNOLOGY \\ HYDERABAD \\ INDIA
}

ALI KENNER

DREXEL UNIVERSITY

UNITEDSTATES

SUJATHA RAMAN

THE AUSTRALIAN NATIONAL

UNIVERSITY

AUSTRALIA

\author{
NOELA INVERNIZZI \\ FEDERAL UNIVERSITY OF \\ PARANÁ \\ BRAZIL
}

\author{
ANGELA OKUNE \\ UNIVERSITY OF \\ CALIFORNIA, IRVINE \\ UNITEDSTATES
}

AMANDA WINDLE
4S SOCIETY FOR SOCIAL
STUDIES OF SCIENCE
UNITED KINGDOM

\author{
DUYGU KAŞDOĞAN \\ IZMIR KATIP ÇELEBI \\ UNIVERSITY \\ TURKEY
}

GRANT JUN OTSUKI
VICTORIA UNIVERSITY OF
WELLINGTON
AOTEAROA NEW ZEALAND

EMILYYORK

JAMES MADISON

UNIVERSITY

UNITEDSTATES

\begin{abstract}
In our inaugural editorial, we, the incoming Editorial Collective (EC) of Engaging Science, Technology, and Society (ESTS), describe the digital and social infrastructural work that we have undertaken since assuming editorship of the journal. We also note some of the changes we have introduced in terms of the journal's content and policies. A key argument is that even though publishing infrastructures shape the form and movement of scholarly content in crucial ways, they often remain black-boxed, rendering invisible the time, labor, and skill in developing and sustaining them.
\end{abstract}

\section{Keywords}

digital infrastructure; open access; Open Journal Systems (OJS); transnational STS; covid-19

We are excited to present the first issue of Engaging Science, Technology, and Society (ESTS) under our editorship. While our editorial collective (EC) formally assumed responsibility for journal content starting January 2021, we began reviewing manuscripts in a graded manner starting April 2020; the new managing editor, Amanda Windle, joined our team in December 2020. This issue reflects many of our deliberations over

Copyright (C) 2021 (Editorial Collective: Aalok Khandekar, Noela Invernizzi, Duygu Kaşdoğan, Ali Kenner, Angela Okune, Grant Jun Otsuki, Sujatha Raman, Amanda Windle, and Emily York). Licensed under the Creative Commons Attribution-NonCommercial-NoDerivatives 4.0 International (CC BY-NC-ND 4.0). Available at estsjournal.org.

To cite this article: Editorial Collective: Khandekar, Aalok, Noela Invernizzi, Duygu Kaşdoğan, Ali Kenner, Angela Okune, Grant Jun Otsuki, Sujatha Raman, Amanda Windle, and Emily York. 2021. "Infrastructuring ESTS." Engaging Science, Technology, \& Society 7.1: 1-11. https://doi.org/10.17351/ests2021.1275. 
the past year and subsequent changes we have introduced in terms of the journal's content and policies. It also materializes, as we discuss in this inaugural editorial, the infrastructuring of ESTS that we have undertaken during this period.

Let us first acknowledge the tremendous service that the outgoing editor, Daniel Kleinman, and the outgoing managing editor, Katie Vann, have done for the $4 \mathrm{~S}$ and the Science and Technology Studies (STS) community writ large in building ESTS as a much sought-after venue for publishing high quality STS research since its founding in 2015. As Kinchy, Parthasarathy, and Delborne (2020) note in their recent editorial, Kleinman and Vann have also been at the forefront of developing new publication genres, pushing the boundaries of what counts as scholarly research and how it is communicated. We owe them a deep debt of gratitude: it is thanks to them that our EC inherited a journal that had already established a solid reputation in a very short time span, and which enjoys so much goodwill among the broader STS community. Authors and reviewers we have worked with have frequently noted their appreciation for ESTS, both because it is an open access (OA) publication and because they have had very positive experiences in working with the journal editors in the past. Our EC hopes to continue and deepen these aspects of the journal.

This legacy notwithstanding, we have still had our work cut out for us. Our EC assumed editorship just as the COVID-19 pandemic was setting in. This meant that like many others, we too were transitioning into remote working routines, dealing with losses to our university communities, juggling childcare, figuring out how best to protect ourselves and our loved ones, and struggling with social, political, and environmental upheavals of various sorts in our different locations. Like many, we have been feeling exhausted. We have tried to be mindful of the fact that writing during disaster can be traumatic and disproportionately burdensome (Pinho-Gomes et al. 2020; Minello 2020; Viglione 2020; Windle 2021). For authors, reviewers, and ourselves alike, we have sought to prioritize self- and collective-care over scholarly productivity. And while we have certainly not paused ESTS publications, this has meant that we have relaxed typical publication timelines.

We also came to our editorial work as a transnational collective, committed to finding ways to leverage the different vantage points of each member of the collective. This diversity within the EC has been intellectually stimulating and creative, further sensitizing us to the ongoing challenge of promoting diversity in how and what we publish. It has allowed us to advance our commitment to making ESTS transnational all the way through, in keeping with the transnational character of $4 \mathrm{~S}$. This has meant that we needed to develop ways to track and expand the locations and lineages of our authors, reviewers, citations, and readers - so that we can better see what and who is included, what and who is missing, and how the journal can actively work against epistemic and academic imperialism. We still have a long way to go, but new structures and processes established in the last few months - that allow us to better see and continually reflect on how we are fulfilling our editorial commitments - are encouraging.

A significant dimension of-and challenge for-our work thus far has been infrastructural. While STS scholars recognize well the labor and organizational work that goes into simply keeping infrastructures functional, let alone vital, practicalities of running a journal with scarce resources means that content 
publication often takes precedence over developing and maintaining publication infrastructures. Editorial workflows and processes, unsurprisingly perhaps, remain under-expressed and under-documented.

Infrastructures, of course, are the stuff of STS. There is a long tradition of scholarship focused on "infrastructure" in the field (e.g., Edwards 2003; ensen and Morita 2015). Indeed, it would not be inaccurate to claim that an attention to and elaboration of infrastructures is one of STS's important contributions to contemporary social theories. In their classic formulation, infrastructures are relational, i.e. they become infrastructures only in relation to other systems of practice. They tend to become visible only when they break down, because infrastructures, when they are effective, tend to fade into the background as a matter of routine practice; most of their users are simply unaware of how they function in the first place (Star and Ruhleder 1996; Star 1999).

In our editorial work thus far, however, we have encountered infrastructures differently. They have been very visible to us, both for what they have allowed us (or not) to do and what goes into making them. However, rather than the ESTS infrastructure breaking down and hence becoming apparent, what we have come to understand, acutely at times, is that we, a geographically distributed collective with experimental sensibilities, were not its anticipated users; it could not easily support participation and workflows spanning transnational time-space.

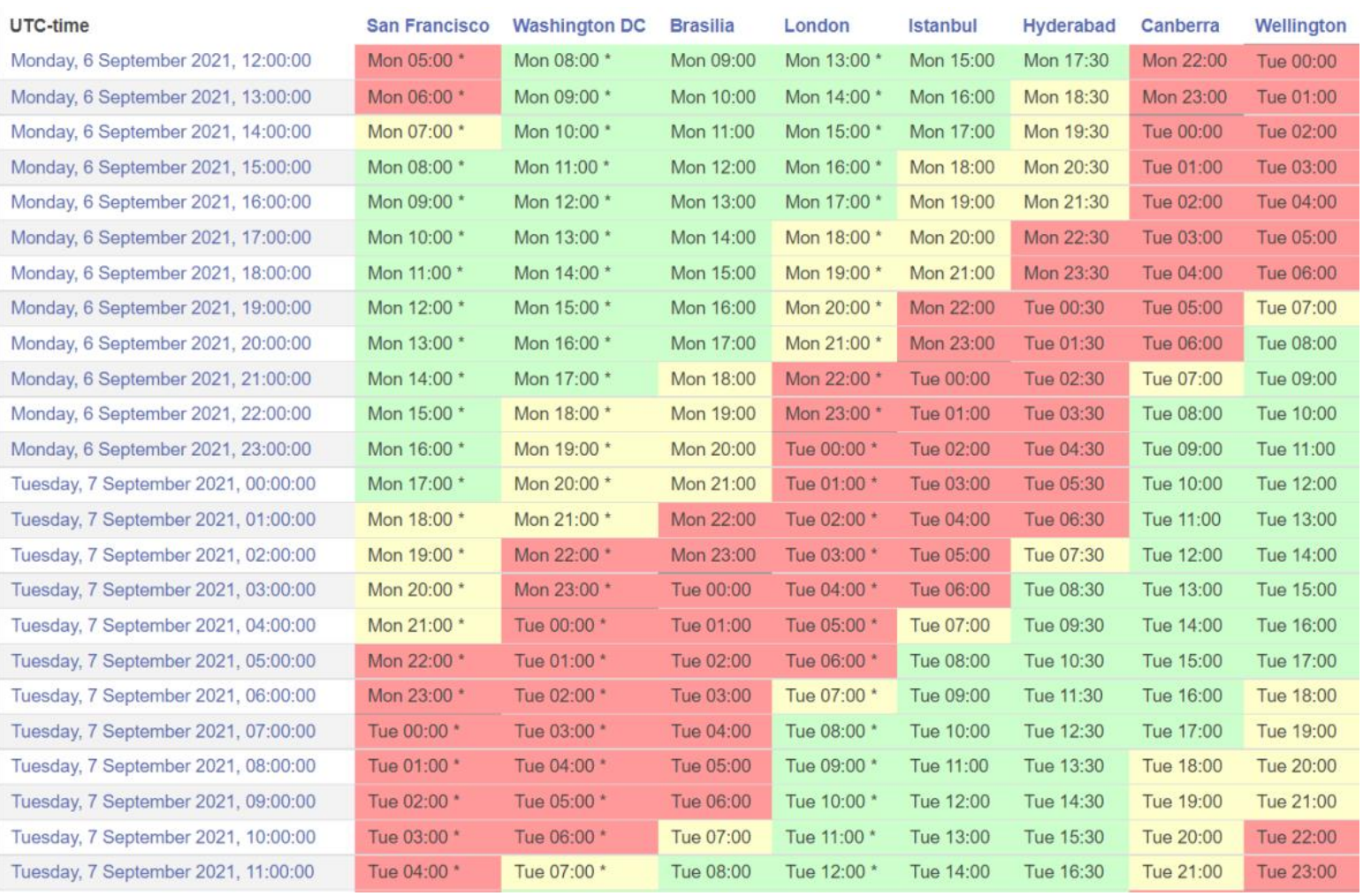

Figure 1. Screenshot showing the time in various time zones in which the EC is based; no single time slot allows for meetings to be scheduled at a time that is simultaneously reasonable for all EC members. 
This has been especially important for us to address: given the different time zones that we all inhabit, it is very impractical to organize frequent editorial meetings (see figure 1). We have, therefore, spent significant time identifying tools and platforms and developing workflows that allow us to operate asynchronously as much as possible. Thus, for example, the EC has maintained a shared journal documenting agendas and action items from its monthly meetings from the very beginning. The journal also includes a global overview of the status of various ESTS initiatives for ready reference. Other tools, like our workspace in Slack, have been important for everyday communication. In discharging her responsibilities as Managing Editor, Amanda Windle has found Asana indispensable, especially because it allows her to visualize and track various journal tasks on a timeline. As the work of the $\mathrm{EC}$ has evolved, the use and configuration of these different tools has had to be periodically revised: in the process of using them, we have had to adjust what tools we use for what purposes and how. We have documented these workflows as resources we can share with others in time.

We note this here not to propose an idealized workflow for journal management, but rather to highlight the insufficiency of any one tool or platform to effectively support the entire spectrum of ESTS activities. This is especially true of working in an open source environment: despite the emergence of new technologies, business models, and infrastructural players resulting from vigorous debates on the social, technical, and economic conditions of academic research publication practice over the past twenty years, ${ }^{1}$ OA today still comes with significant hurdles and requires investment of resources often beyond what academic organizations can commit (see Eve and Gray (2020) for more on the latest developments in OA scholarly publishing). For us, this was particularly evident when we upgraded the journal's content management system, Open Journal Systems (JS $)$, from version 2.0 to 3.1. In arriving at the decision to upgrade to OJS 3.1, we explored alternative open source platforms for hosting ESTS, but in the end concluded that while other

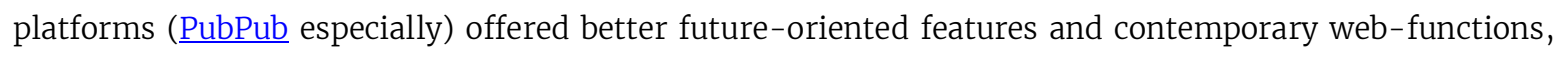
OJS was still a more stable and well-documented platform for providing standard journal production functions. OJS's more conventional imagination of scholarly journals, however, has meant that it is less infrastructured for supporting the production of content in new formats (HTML in addition to PDF, for example, as we have implemented starting this issue) and leveraging the experimental possibilities of virtual space for a digital only journal like ESTS. We have had to raise countless service request tickets with OJS's developers, the Public Knowledge Project ( $\underline{\mathrm{PKP}})$, in order to work through the platform's embedded assumptions and limitations. We have sometimes also had to figure out workarounds and indeed-at considerable time and expense-develop our own tools (as we have, for instance, in case of the bespoke tool to produce content in HTML format). And while OJS remains integral to the everyday functioning of ESTS,

${ }^{1}$ In 2002, three declarations on Open Access were published: the "triple-Bs" of Bethesda, Budapest, and Berlin (Eve and Gray 2020). Open access, as conceptualized in these declarations, promised to use the power of the internet to make research work freely available to anyone who wants to read it. One of the first free software platform for the management of peer-reviewed academic journals, the Open Journal Systems (OJS), was released in 2001 by the Public Knowledge Project as part of this emergent ecosystem around Open Access scholarly publishing. 
our overall infrastructural approach has had to become far more hybridized, working through a very wide array of proprietary and open source tools, platforms, and supporting protocols - difficult to keep up with at times, further reinforcing the need for well-articulated archival and documentary practices.

Other aspects of our editorial work have been more routine. We have expended significant time and attention in developing templates and protocols for ESTS. From author submission forms and reviewer guidelines to production checklists and everything in between, the EC has iterated through multiple drafts of each. Governance procedures for the journal have been revised as well (in conformity with COPE guidelines, among other considerations), published on the journal website and archived as editable documents for future iterations, by us and our successors.

One place in which our infrastructural work is visible is the redesigned ESTS website, which was launched in April 2021. The immediate reason for redoing the website was that the version of OJS that ESTS was previously using was no longer going to be supported by PKP. We decided to use the occasion to incorporate findings from the ESTS reader survey that we hosted in late 2020, as well as insights that we had gained from our own research into the landscape of OA publishing more generally to upgrade not only the journal's content management system, but also its website, policies, and communication strategies (see working document compiling our background research on an ongoing basis (Windle and ESTS Editorial Collective 2021)). Table 1 offers a quick overview of various activities that the EC has undertaken since assuming editorship of ESTS. Worth emphasizing here is that upgrading the journal website has been much more than just that: it has entailed the design of an entire information ecosystem, now deliberately infrastructured to promote diversity in terms of form, content, access, and participation.

\begin{tabular}{|l|l|l|}
\hline Project Management for ESTS Editorial Collective \\
\hline $\begin{array}{l}\text { Communication and coordinating } \\
\text { workflow }\end{array}$ & $\begin{array}{l}\text { Identifying necessary tools, protocols, and platforms for supporting } \\
\text { transnational editorial workflows: currently a combination of OJS, Google Suite, } \\
\text { Slack, Asana }\end{array}$ \\
- $\begin{array}{l}\text { Organizing weekly meetings between the Editor-in-Chief and Managing Editor, } \\
\text { monthly meetings for the EC, and occasional meetings to discuss and workshop } \\
\text { new initiatives } \\
\text { Maintaining a journal for the EC with agendas of and action items from monthly } \\
\text { EC meetings, and global overviews of various ESTS initiatives }\end{array}$ \\
\hline Rigital infrastructure & $\begin{array}{l}\text { Conducting reader survey to understand ESTS user practices and needs } \\
\text { Evaluating existing platforms for OA publishing, most notably PubPub, prior to } \\
\text { deciding on upgrading to OJS version 3.1 } \\
\text { Conducting "landscape survey" of journals in STS and related fields, both OA } \\
\text { and those supported by commercial publishers, identified through ESTS reader } \\
\text { survey and domain expert consultations in order to identify salient orientations } \\
\text { for redesigning journal website, governance processes, and communication } \\
\text { strategies }\end{array}$ \\
\hline Upgrading to OJS 3.1 & $\begin{array}{l}\text { Training on new version of OJS } \\
\text { Developing editorial workflow through the upgraded system, including the } \\
\text { ability to track flows in the system all the way from initial submission and } \\
\text { review to production }\end{array}$ \\
\hline
\end{tabular}




\begin{tabular}{|c|c|}
\hline Website upgradation & $\begin{array}{l}\text { - Developing a visual identity for ESTS, choosing contemporary free and open } \\
\text { source font (Merriweather) suitable for ESTS purposes, and designing } \\
\text { supporting images and graphics, including logo, thumbnail, favicon, banner } \\
\text { image, letterhead, slide templates, and a new color palette } \\
\text { Evaluating existing ESTS website for accessibility and designing new website to } \\
\text { better support access for a diversity of users and interfaces (mobiles, tablets, } \\
\text { and laptops) } \\
\text { Designing and testing the new website in a sandbox environment; Redeveloping } \\
\text { website freshly in live instance }\end{array}$ \\
\hline \multicolumn{2}{|l|}{ Governance } \\
\hline Journal policies & $\begin{array}{l}\text { - Revising journal polices based on a review of COPE guidelines and publication } \\
\text { policies of journals in related fields } \\
\text { - Simplified publication genres and corresponding author guidelines to continue } \\
\text { encouraging experiments in the form of scholarly writing } \\
\text { - Developing reviewer guidelines to enable and support transnational } \\
\text { participation in ESTS } \\
\text { - Initiating development of transnational reviewer database }\end{array}$ \\
\hline Editorial board & $\begin{array}{l}\text { - Constituting new editorial board with members from about } 40 \text { nations and } \\
\text { across career stages to advise and help EC in cultivating and promoting } \\
\text { "transnational STS" }\end{array}$ \\
\hline Data & $\begin{array}{l}\text { - } \quad \text { Pursuing conformance with GDPR regulations } \\
\text { - Reviewing } 12,000+\text { users in journal system }\end{array}$ \\
\hline \multicolumn{2}{|l|}{ Submissions management } \\
\hline Submission to review workflow & $\begin{array}{ll}\text { - } & \text { Auditing and revising email templates to work in OJS } 3.1 \\
\text { Designing workflow, timeline, and checklist for journal editors }\end{array}$ \\
\hline Production workflow & $\begin{array}{l}\text { - } \quad \text { Designing final submission form for authors } \\
\text { - } \quad \text { Designing and implementing new galley files } \\
\text { - } \quad \text { Creating bespoke tool (using Javascript, PHP, and Python integrated with Colab } \\
\text { (Google's machine learning platform) and Mammoth terminal) to ESTS } \\
\text { technical specifications for HTML conversion } \\
\text { Developing and implementing software code and designing workflow to publish } \\
\text { in both PDF and HTML formats }\end{array}$ \\
\hline \multicolumn{2}{|l|}{ Communications and outreach } \\
\hline Social media & $\begin{array}{l}\text { Developing promotions strategy for ESTS, including active use of Twitter } \\
\text { (resulting in a steady increase of journal's reach, by measuring growth in } \\
\text { followers and user-engagement) }\end{array}$ \\
\hline Press & $\begin{array}{l}\text { - Introducing ESTS editorial team and vision through blog posts on Backchannels } \\
\text { and IstanbuLab }\end{array}$ \\
\hline Newsletter & $\begin{array}{l}\text { Establishing Mailchimp-based newsletter for promoting journal initiatives and } \\
\text { publications }\end{array}$ \\
\hline Google analytics & $\begin{array}{l}\text { - Designing and implementing analytics strategy to measure reach and } \\
\text { effectiveness of ESTS content and website }\end{array}$ \\
\hline Community building & $\begin{array}{l}\text { - Convening roundtables and meet ups at 4S } 2021 \text { to create opportunities for } \\
\text { interacting with and deepening awareness of ESTS functioning and needs } \\
\text { among the journal community }\end{array}$ \\
\hline
\end{tabular}




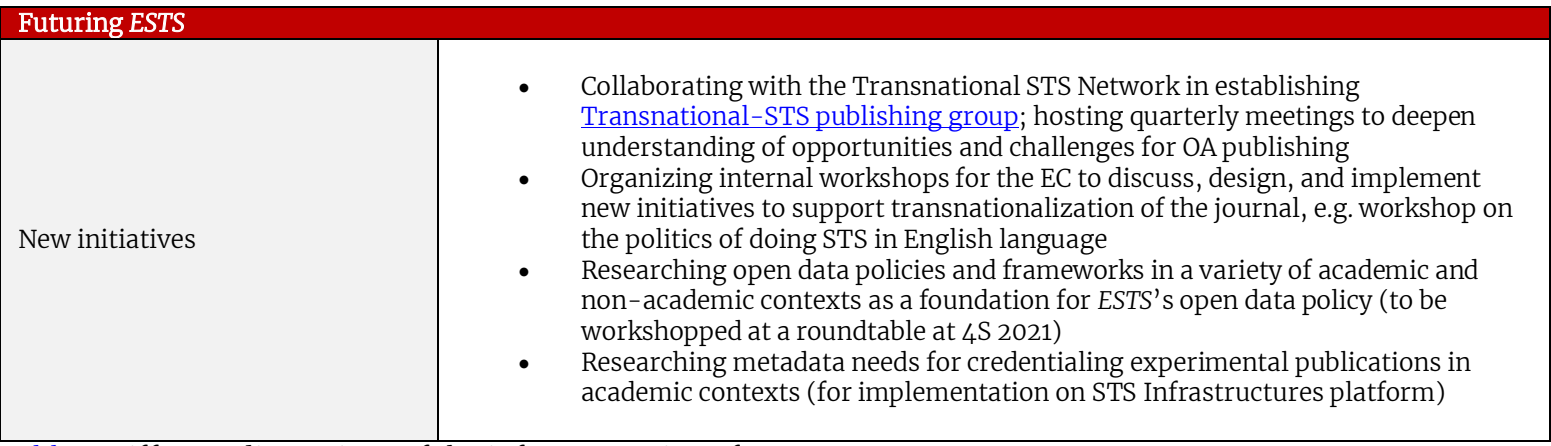

Table 1. Different dimensions of the infrastructuring of ESTS.

As authors and editors, we are accustomed to thinking about the publication process primarily in terms of navigating through and managing the peer review process. This is, of course, a bedrock of scholarly publishing; yet, focusing on this alone obfuscates the time, labor, and skill required for figuring out underlying digital and social infrastructures that configure and enable the movement of scholarly content from initial submission through final production in important ways (see also Kenner (2014) for an account of the long-term socio-technical work of designing digital infrastructure to transition the journal, Cultural Anthropology, to OA). In building ESTS's digital infrastructure, we have realized and had to grapple with the extent to which the process of academic publishing tends to be black-boxed. As one way to realize our commitment to deepen OA publishing, it is our intention to open source the infrastructural resources that we have been developing for broader circulation and uptake in the coming days.

We will say more about our efforts to cultivate and support "transnational STS" in subsequent issues; for now, we will note that doing so is as much an infrastructural challenge as it is a political and intellectual one. Existing tools and infrastructures do not readily lend themselves to fostering a transnational STS community; they need to be designed, developed, repurposed, and continually iterated. Transnational STS thus becomes a design challenge, articulated importantly through its underlying infrastructures.

\section{Issue 7.1}

With the publication of this issue, we are transitioning away from a model of continuous publication in a single annual volume to an issue-based one. This transition will allow us to better plan journal operations and promotional strategies to help amplify the impact of our publications. We have also simplified ESTS's publication genres into three broad categories: Original Research Articles, Engagements, and Perspectives. We continue to maintain an open call for proposals on Thematic Collections as well. Original Research Articles will feature scientific publications showcasing the breadth of STS scholarship; Engagements contributions will accommodate the different novel and experimental formats that ESTS previously featured and encourage new ones; Perspectives contributions will include topical reflections on matters of interest to more-thanjust-STS audiences. Thematic Collections can now feature contributions from across different publication genres rather than only research articles. Readers can consult our website for further details; here, we will simply note that even though we have modified our publication genres, we intend for ESTS to continue being a space for experimenting with the form and content of scholarly publications in the broadest manner. 
This issue includes four Original Research Articles that converge, although not by design, around a thematic of data infrastructures. Estrid Sørensen and Laura Koksch's essay examines how data is made "durable" by scientists at a German university in the context of increased demands for data sharing and reuse. Luzilda Arciniega's essay examines ways in which corporate bureaucrats extend a Du Boisian legacy in their deployment of visual and rhetorical strategies aimed at ensuring diversity in the workplace. Andrea Ford, Guilia De Togni, and Livia Miller's essay highlights the use of period-tracking apps beyond the reproductive imperative and ways in which this engenders complex techniques of self-management. Both essays underscore the ultimate tension that animates contemporary data infrastructures: they facilitate, as Ford, De Togni, and Miller put it, "success within flawed structures." While securing justice and empowerment for marginalized individuals and groups at one level, they nonetheless leave intact structures of systemic discrimination. James Merron and Luregn Leggenhager further alert us to uncritical celebrations of the liberatory potential of infrastructure, arguing that environmental conservation efforts and militarization have evolved hand-in-hand in the Namibia-South Africa border region, made possible through shared infrastructure and socio-technical practices.

The Engagements section hosts a forum celebrating the work of one of the $20204 \mathrm{~S}$ Bernal Prize recipients, Langdon Winner. We are delighted to publish Winner's Bernal prize lecture and invited commentaries from diverse scholars to his lecture and the broader influence of his scholarship. Michael Bennett offers introductory remarks to Langdon Winner's Bernal Prize forum, describing the significance of several recurrent figures in Winner's writings. Contributions by Belén Albornoz, Alfred Nordmann, Ernst Schraube, and Sujatha Raman then take up the travels of Winner's work across disciplinary and geographical boundaries, highlighting the continuing relevance of his work to urgent questions of the day. Our subsequent issue will host a forum dedicated to the scholarship of Sharon Traweek, another 2020 4S Bernal Prize recipient.

Drawing on controversies surrounding the now-deferred roll out of a health data sharing initiative - the General Practice Data for Planning and Research (GPDPR) - by the UK's National Health Service (NHS), Bharti et al.'s contribution to the Perspectives section, Public Trust, Deliberative Engagement, and Health Data Projects, highlights the indispensability of deliberative public engagement in defining and implementing how health data is mobilized for medical research and innovation. The essay succinctly brings decades of STS research to bear on a key contemporary matter of concern in an eminently accessible manner-we hope for such contributions to be a regular feature in ESTS pages.

Transnationally, technosciences are fundamentally caught up in almost every aspect of contemporary life, creating both opportunities and challenges, often unevenly distributed. As contributions to this issue attest, STS can help understand the many entanglements of technosciences and societies. It can also help shape these in ways that are more just and inclusive. Doing so, we have suggested in this editorial, entails deliberate infrastructuring. We invite our readers to explore these and related matters in the present issue and join our ongoing efforts to cultivate, infrastructure, and sustain open, inclusive, and transnational communities and agendas in STS that can help formulate responses to the many urgent questions of the day. 


\section{Author Biographies}

The Editorial Collective for Engaging Science, Technology, and Society (ESTS) is responsible for day-to-day operations of the journal. It includes:

Aalok Khandekar, Editor-in-Chief, and an assistant professor of Anthropology/Sociology at the Indian Institute of Technology, Hyderabad, India. As part of the Cool Infrastructures consortium, his current research examines thermal knowledges and practices as marginalized groups in the urban global South adapt to rising temperatures in their cities. Khandekar was lead curator of the STS Across Borders and Innovating STS exhibits at the 2018 and 2019 4S annual meetings and is a founding member of the Transnational STS and TransAsiaSTS networks.

Noela Invernizzi, Associate Editor, is a Uruguayan anthropologist with a PhD in Science and Technology Policy (State University of Campinas, Brazil). She is a full professor at the Education Sector and the Public Policy Graduate Program of the Federal University of Parana, in Brazil. Her research interests include the effects of industrial innovation for workers' skills and employment conditions; science, technology, and innovation policies; the development of nanotechnology in Latin American countries, and the practices and politics of academic science evaluation.

Duygu Kaşdoğan, Associate Editor, is assistant professor of Urbanization and Environmental Problems in the Department of Political Science and Public Administration at İzmir Katip Çelebi University, Turkey. She received her doctoral degree in Science and Technology Studies Program at York University, Canada. She is the founding member of IstanbuLab and Transnational STS Network, and council member in $4 \mathrm{~S}$ since September 2019. Her research focuses on democratization of science, transnational collaboration, political ecology of disasters, toxicity governance, and bioeconomies.

Ali Kenner, Associate Editor, is an associate professor in the Department of Politics and the Center for Science, Technology, and Society at Drexel University. Her current research focuses on energy justice in the U.S. Mid-Atlantic region, and the tensions between sustainable transitions and energy vulnerability. Kenner is the author of Breathtaking: Asthma Care in a Time of Climate Change (2018) and a member of Climate Ready Philly.

Angela Okune, Associate Editor, studies research data practices and infrastructures in Nairobi, Kenya to explore questions of equity, knowledge production and open science in Africa. She is completing her doctorate in the Department of Anthropology at the University of California, Irvine in 2021. Angela provided strategic guidance for the growth of tech research in Kenya as co-founder of iHub Research (2010-2015). Angela is co-editor of the open-access book Contextualizing Openness (2019).

Grant Jun Otsuki, Associate Editor, is a lecturer in cultural anthropology at Victoria University of Wellington, New Zealand. He has a PhD in anthropology (Toronto), and an MS in STS (RPI). Previously, he was assistant professor of anthropology, University of Tsukuba, Japan. His work is in the anthropology and history of 
technology. Grant has written about human-machine interfaces and the history of cybernetics in Japan, postcolonial anthropology, translation, and the anthropology of ethics in Japanese and English.

Sujatha Raman, Associate Editor, is associate professor and director of research at the Centre for Public Awareness of Science (CPAS), Australian National University. Her research explores the role of expertise and publics in policy; responsible innovation; and transitions in energy, environment and health from a transdisciplinary STS perspective. She is the former co-director of the Institute for Science \& Society (ISS), University of Nottingham, UK and co-editor of Science and the Politics of Openness (2018).

Amanda Windle, Managing Editor, Amanda Windle brings an academic background to an editorial portfolio that includes ESTS and the Interactions magazine. Her PhD in design and STS led to research focusing on feminisms and the digital design of online technologies. At present her research interests bridge disaster trauma, digital design, disability and editorial matters. Windle is a training psychotherapist at the Guild (London), chair of the Simon Community London, $4 \mathrm{~S}$ council member, and author of $\underline{A}$ Companion of Feminisms for Digital Design and Spherology (2019).

Emily York, Associate Editor, is an assistant professor in the School of Integrated Sciences at James Madison University. She has a PhD in Communication and Science Studies (University of California San Diego). Integrating STS research and teaching into STEM spaces is a key emphasis of her practice and intellectual inquiry. Her research focuses on STS pedagogy, interdisciplinary collaboration, critical participation, responsible innovation, and future-making within high tech innovation and higher education. She is a founder and co-director of the STS Futures Lab.

\section{References}

Edwards, Paul. 2003. "Infrastructure and Modernity: Force, Time, and Social Organization in the History of Sociotechnical Systems." In Modernity and Technology, edited by Thomas J. Misa, Philip Brey, and Andrew Feenberg, 187-226. Cambridge, MA: MIT Press.

Eve, Martin Paul, and Jonathan Gray, eds. 2020. Reassembling Scholarly Communications: Histories, Infrastructures, and Global Politics of Open Access. Cambridge, MA: MIT Press.

Jensen, Casper Bruun, and Atsuro Morita. 2015. "Infrastructures as Ontological Experiments." Engaging Science, Technology, and Society 1: 81-87. https://doi.org/10.17351/ests2015.21.

Kenner, Ali. 2014. "Designing Digital Infrastructure: Four Considerations for Scholarly Publishing Projects." Cultural Anthropology 29(2): 264-87. https://doi.org/10.14506/ca29.2.05.

Kinchy, Abby J., Shobita Parthasarathy, and Jason Delborne. 2020. "A Five-Year Engagement." Engaging Science, Technology, and Society 6: 411-15. https://doi.org/10.17351/ests2020.749.

Minello, Alessandra. 2020. "The Pandemic and the Female Academic." Nature April 2020. https://doi.org/10.1038/d41586-020-01135-9.

Pinho-Gomes, Ana-Catarina, Sanne Peters, Kelly Thompson, Carinna Hockham, Katherine Ripullone, Mark Woodward, and Cheryl Carcel. 2020. "Where Are the Women? Gender Inequalities in COVID-19 Research Authorship." BMJ Global Health 5(7): e002922. https://doi.org/10.1136/bmigh-2020$\underline{002922 .}$ 
Star, Susan Leigh. 1999. "The Ethnography of Infrastructure." American Behavioral Scientist 43(3): 377-91. https://doi.org/10.1177/00027649921955326.

— - and Karen Ruhleder. 1996. "Steps Toward an Ecology of Infrastructure: Design and Access for Large Information Spaces." Information Systems Research 7(1): 111-34.

Viglione, Giuliana. 2020. "Are Women Publishing Less during the Pandemic? Here's What the Data Say." Nature 581(7809): 365-66. https://doi.org/10.1038/d41586-020-01294-9.

Windle, Amanda. 2021. "Journey of a Backchannels Editor, Around a Thousand Words." Backchannels (blog), Society for Social Studies of Science. April 19, 2021. https://www.4sonline.org/journey-of-abackchannels-editor-around-a-thousand-words/.

_ _ and ESTS Editorial Collective. 2021. "ESTS Redesign Scoping Document." Contributed by Engaging Science, Technology, and Society Journal. STS Infrastructures, Platform for Experimental Collaborative Ethnography. September 29, 2021. Last modified October 3, 2021, accessed October 4, 2021. https://stsinfrastructures.org/content/ests-redesign-scoping-document. 